\title{
Relationship between bone mineral density and
} the risk of breast cancer: a systematic review and dose-response meta-analysis of ten cohort studies

\author{
Jian-Hua Chen' \\ Quan Yuan' \\ Ya-Nan $\mathrm{Ma}^{2}$ \\ Shi-Han Zhen ${ }^{2}$ \\ De-Liang Wen ${ }^{2}$ \\ 'Department of Orthopaedics, \\ Shengjing Hospital of China \\ Medical University, Shenyang, China; \\ 2Department of Health Policy and \\ Management, School of Public Health, \\ China Medical University, Shenyang, \\ China
}

This article was published in the following Dove Medical Press journal: Cancer Management and Research

\begin{abstract}
Purpose: The evidence from recent epidemiological studies investigating the relationship between bone mineral density (BMD) and the risk of breast cancer (BC) remains inconsistent. Materials and methods: The PubMed, EMBASE, and Web of Science databases were comprehensively searched by two independent authors to identify related cohort studies from the inception of the databases through January 31, 2018. Similarly, two researchers separately extracted the data from the selected studies, and any differences were resolved by discussion. Summarized relative risks (RRs) and 95\% CIs were summarized via inverse variance weighted random-effects meta-analysis. Heterogeneity among studies was assessed with the $I^{2}$ statistic. Results: Ten studies with 1,522 BC patients among 81,902 participants were included in this meta-analysis. Compared to the participants with the lowest BMD at the lumbar spine, those with the highest BMD had a significantly lower $\mathrm{RR}$ for $\mathrm{BC}(\mathrm{RR}=0.75 ; 95 \% \mathrm{CI}=0.60-0.93$; $P^{2}=23.0 \%$ ). In the subgroup analyses, although the directions of the results were consistent with those of the main findings, not all showed statistical significance. We failed to detect an association between BMD at the femoral neck or total hip and the risk of BC (RR $=0.94 ; 95 \%$ $\mathrm{CI}=0.66-1.33 ; P^{2}=72.5 \%$ ). Furthermore, the results of the dose-response analysis did not show a significant association between BMD at the lumbar spine, femoral neck, or total hip and the risk of BC. Funnel plot and statistical analyses showed no evidence of publication bias.

Conclusion: There is no relationship between BMD and the risk of BC. More prospective
\end{abstract} cohort studies are warranted to further investigate this issue.

Keywords: bone mineral density, breast cancer, cohort studies, meta-analysis, risk

\section{Introduction}

Breast cancer (BC) is the most common cancer (excluding non-melanoma skin cancer) among women worldwide. ${ }^{1}$ Unsurprisingly, in 2018, BC was expected to account for $30 \%$ of all new cancer diagnoses in women in the USA. ${ }^{2}$ Recently, estrogen has been proven to play an important role in the development and progression of this disease in numerous studies. Several risk factors for BC have been identified, many of which (eg, age at menarche, age at menopause, breastfeeding, and hormone replacement therapy [HRT]) are related to prolonged estrogen exposure. ${ }^{3}$ Furthermore, it is noteworthy that more than three-quarters of all BC and $85 \%$ of BC-related deaths occur in postmenopausal women.

Bone mineral density (BMD) is an essential component of the assessment of bone quality and is utilized to assess the osteoporotic status of the bone for the prevention of osteoporotic fractures. The standard method of assessing BMD is dual-energy X-ray
Correspondence: De-Liang Wen Department of Health Policy and Management, School of Public Health, China Medical University, No. 77, Pu He Road, Shenyang, Liaoning 110122 , China Tel +8602431939022

Email dlwen@cmu.edu.cn 
absorptiometry (DXA) of the lumbar spine (LS), femoral neck (FN), or total hip (TH). Moreover, because estrogen regulates bone turnover by inhibiting bone resorption and upregulating hormones that enhance bone formation, ${ }^{4}$ high BMD is regarded as a marker of prolonged cumulative lifetime exposure to estrogen, 5,6 and high BMD serves as an intermediate marker of BC risk. Although the number of prospective cohort studies exploring the role of BMD in the risk of $\mathrm{BC}$ has been increasing, ${ }^{7-16}$ the findings have been inconsistent. This inconsistency might be attributed to different study designs, menopausal status of participants, and BMD measurement methods and sites. Although Nagel et $\mathrm{al}^{7}$ performed a meta-analysis of this topic, the aforementioned differences still existed in their study. Herein, to further clarify the association between BMD and the risk of $\mathrm{BC}$, we performed a systematic review and meta-analysis using currently available evidence from cohort studies.

\section{Materials and methods}

\section{Search strategy}

We carried out a systematic review of English language articles published from the inception of the databases to the end of January 2018 in PubMed, EMBASE, and Web of Science that reported the association between BMD and the risk of $\mathrm{BC}$ with the following search algorithm: "(bone mineral density OR bone density OR BMD OR osteoporosis) AND (breast) AND (cancer OR neoplasm OR carcinoma OR tumour OR malignancy OR malignancies)". Figure 1 shows the flowchart detailing the process of identifying eligible studies; 12,040 abstracts were reviewed (by J-HC and QY). We followed the guidelines of the PRISMA. ${ }^{17}$

\section{Study selection and exclusion}

Paired reviewers ( $\mathrm{J}-\mathrm{HC}$ and QY) who have been trained in research methods both independently screened the titles/ abstracts and full texts to identify eligible articles, assessed the risk of bias, and extracted data from each eligible study using standardized pilot-tested forms with detailed instructions. Reviewers resolved discrepancies through discussion or, if necessary, arbitration by a third reviewer (S-HZ).

Cohort studies that contained extractable information on BMD and BC outcomes were eligible. Furthermore, studies were included if they reported the relative risks (RRs) with $95 \%$ CIs or reported sufficient data to allow the calculation of those risk estimates. We excluded studies that met the following criteria: 1) case-control studies, randomized controlled trials, case reports, editorials, ecological studies, and reviews without original data and 2) studies that failed to provide risk estimates and 95\% CIs. If multiple studies had the same participant cohort, only the study with the largest sample size was included for any given outcome.

\section{Data extraction and quality assessment}

Data were extracted in duplicate by two independent authors (J-HC and QY) using standardized forms. Disagreements were resolved by consensus. A single investigator (J-HC) extracted the following information from each included study: first author, publication year, geographic location, number of BC patients and controls, BMDs of BC patients and controls, site of BMD measurement, exposure category, and study-specific adjusted RRs with 95\% CIs. For risk estimates, if both univariate and multivariate analyses were provided, data from multivariate analysis were extracted; otherwise, data from univariate analysis were used. The extracted data were entered into a standardized Excel spreadsheet (Microsoft Corporation, Redmond, WA, USA). The quality of each study was assessed according to the Newcastle-Ottawa Scale (NOS) ${ }^{18}$ by two authors (J-HC and QY) independently.

\section{Statistical analysis}

The RRs and 95\% CIs are presented as summaries of the risk estimates; the RRs were calculated with a random-effects model to investigate the association between BMD and the risk of BC. For studies that only provided the results of a dose-response analysis, we used the scaling method proposed by Danesh et al $^{19}$ to convert the reported risk estimates into a standard scale of effect to compare persons with levels of exposure in the top tertile to persons with exposure levels in the bottom tertile. More details about this method can be obtained elsewhere. For studies that did not use the lowest category of BMD as the reference, ${ }^{8-10,12,14}$ we used the effective counts method proposed by Hamling et $\mathrm{al}^{20}$ to recalculate the RRs and 95\% CIs.

The method described by Greenland and Longnecker ${ }^{21}$ was used for the dose-response analysis, and study-specific slopes (linear trends) and 95\% CIs were computed from the natural logs of the RRs and CIs across categories of BMD values. This method requires that the distribution of cases and person-years or non-cases and RRs with variance estimates are known for at least three quantitative exposure categories. We assigned the median or mean level of BMD in each category to the corresponding RR for each study. For studies that reported ranges of BMD values, we estimated the midpoint in each category by calculating the average of the lower and upper bounds. When the highest category was open ended, we assumed the length of the open-ended interval to 

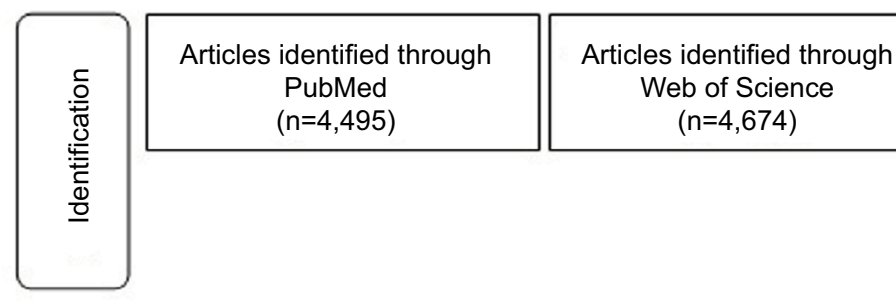

Articles identified through EMBASE $(n=2,871)$
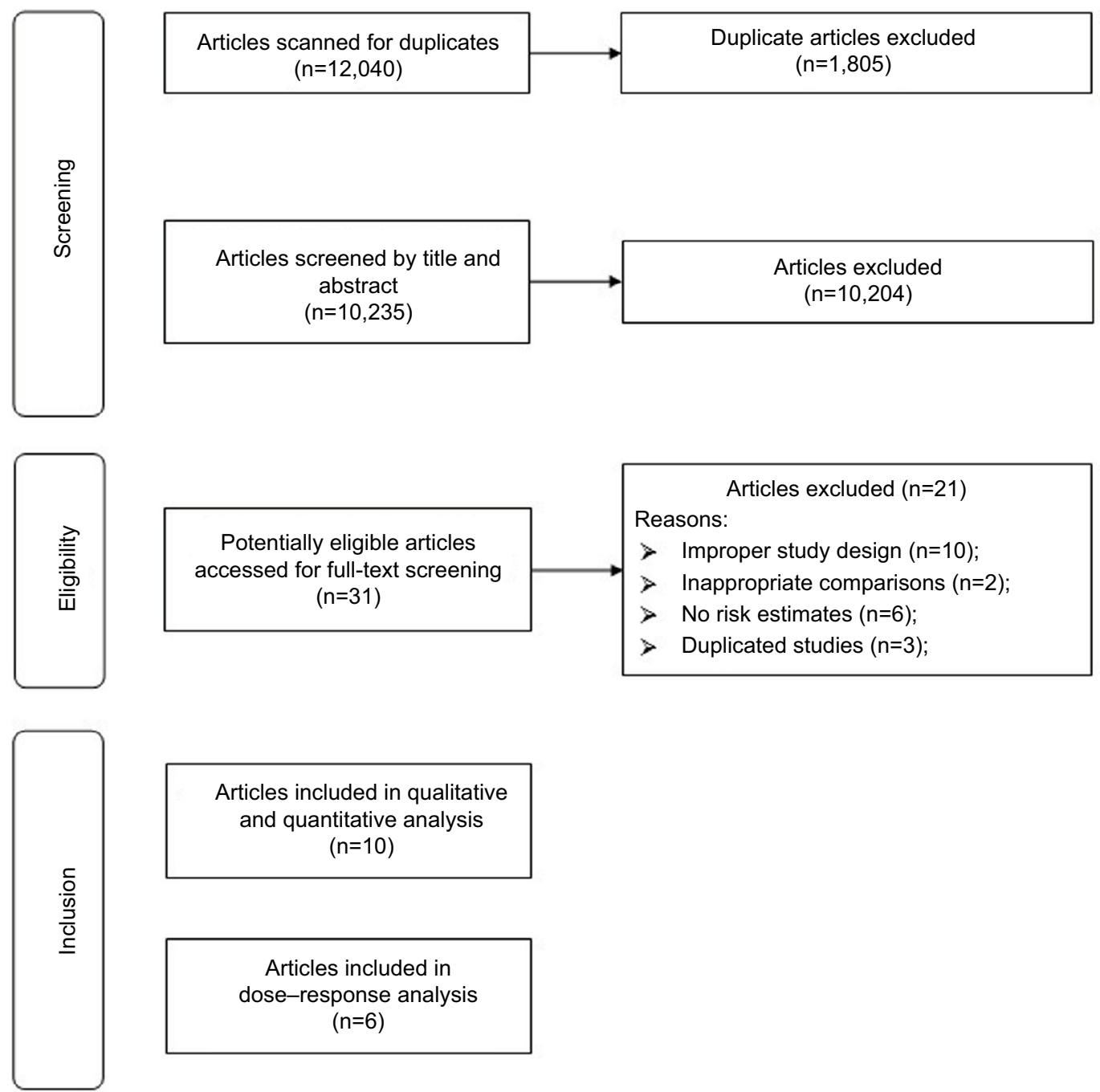

Figure I Selection of studies for inclusion in this meta-analysis.

be the same as that of the adjacent interval. When the lowest category was open ended, we set the lower boundary to zero. The dose-response results in the forest plots are presented for $0.1 \mathrm{~g} / \mathrm{cm}^{2}$ increments in BMD.

$I^{2}$ statistic was used to assess the heterogeneity between studies, ${ }^{22}$ which was the amount of total variation that is explained by the variation between studies. ${ }^{22}$ Heterogeneity between subgroups was evaluated by meta-regression. Post hoc subgroup analyses were conducted according to the geographic location (North America, Europe, and others), median number of $\mathrm{BC}$ cases $(\geq 50 \mathrm{vs}<50)$, exposure unit ( $\mathrm{g} / \mathrm{cm}^{2}$ vs others), study quality (low risk of bias vs high risk of bias), and menopausal status of participants (postmenopausal vs not postmenopausal), and adjustments were made for potential confounders (including body mass index, menopausal status, HRT use, and any reproductive factors).

We generated a funnel plot and applied Egger's test ${ }^{23}$ and Begg's test ${ }^{24}$ to examine publication biases (eg, publication bias), with $P<0.10$ indicating the presence of bias. In addition, we visually explored the funnel plots for asymmetry. 
We carried out sensitivity analyses by removing one study at a time to examine the effect of the data from each study on the overall estimate. The sequential exclusion strategy proposed by Patsopoulos et $\mathrm{al}^{25}$ was used to determine whether the overall estimates were influenced by the substantial observed heterogeneity. Studies that accounted for the largest proportions of the heterogeneity were sequentially and cumulatively excluded until $I^{2}$ was $<50 \%$. Then, further examinations were conducted to determine whether the risk estimates were consistent before and after the exclusion of those studies. ${ }^{26}$ All statistical analyses were performed using the Stata statistical software package (version 12.0; StataCorp LP, College Station, TX, USA).

\section{Results}

\section{Search results, study characteristics, and quality assessment}

In total, 12,040 articles on BMD and BC risk were screened for inclusion (Figure 1). After the removal of duplicates, 9,937 articles were screened via title and abstract to determine those eligible for full-text review. In total, 36 articles were selected for full-text review. Sixteen articles were excluded for various reasons. Finally, ten articles were selected for inclusion in this systematic review and meta-analysis.

The main characteristics of the ten included cohort studies are presented in Table 1. Most of the included studies were conducted in Europe $(n=5)$ and North America $(n=4)$, and one was conducted in Asia. All included studies included data on DXA scanning at the baseline but at different positions, including the LS, FN, and TH. Nine, eight, seven, and five studies adjusted for age, body mass index, menopausal status, and HRT use, respectively, while fewer studies adjusted for cigarette smoking $(n=3)$, physical activity $(n=3)$, alcohol consumption $(n=2)$, and parity $(n=2)$. None of the included studies adjusted for race (Table 2).

Table 3 provides the details of the study quality assessment as reflected by the NOS scores.

\section{$B M D$ and $B C$ risk (highest vs lowest category)}

We found that compared with participants with the lowest BMD at the LS, participants with the highest BMD had $\sim 0.75$-fold the risk of BC $\left(95 \% \mathrm{CI}=0.60-0.93 ; I^{2}=23.0 \%\right.$; $P$ for heterogeneity $=0.254 ; \mathrm{n}=7$ ), as shown in Figure 2 . In

Table I Characteristics of the included cohort studies

\begin{tabular}{|c|c|c|c|c|c|c|}
\hline $\begin{array}{l}\text { Author, year, } \\
\text { country }\end{array}$ & $\begin{array}{l}\text { No. of cases } \\
\text { (mean age, } \\
\text { years) }\end{array}$ & $\begin{array}{l}\text { BMD of } \\
\text { cases (mean, } \\
\mathrm{g} / \mathrm{cm}^{2} \text { ) }\end{array}$ & $\begin{array}{l}\text { No. of controls/ } \\
\text { cohort (mean } \\
\text { age, years) }\end{array}$ & $\begin{array}{l}\text { BMD of } \\
\text { controls/cohort } \\
\left(\text { mean, } \mathrm{g} / \mathrm{cm}^{2}\right)\end{array}$ & $\begin{array}{l}\text { Position } \\
\text { (assessment) }\end{array}$ & $\begin{array}{l}\text { Exposure } \\
\text { category }\end{array}$ \\
\hline $\begin{array}{l}\text { Nagel et al,, } 2017 \text {, } \\
\text { Germany }\end{array}$ & $52(55.1)$ & LS (0.92) & $\mathrm{I}, 380(55.5)$ & LS (0.96) & LS (DXA) & $\begin{array}{l}\text { Quartile per I z } \\
\text { score increase }\end{array}$ \\
\hline $\begin{array}{l}\text { Fraenkel et al, }{ }^{8} \\
2013, \text { Israel }\end{array}$ & $86(68.8)$ & $\begin{array}{l}\text { LS (I.04) } \\
\text { FN (0.84) } \\
\text { TH }(0.91)\end{array}$ & $15,268(65.1)$ & $\begin{array}{l}\text { LS }(\mathrm{I} .00) \\
\mathrm{FN}(0.8 \mathrm{I}) \\
\mathrm{TH}(0.88)\end{array}$ & LS/FN/TH (DXA) & Tertile \\
\hline $\begin{array}{l}\text { Grenier et al, }{ }^{9} 201 \mathrm{l}, \\
\text { Canada }\end{array}$ & $794(64.7)$ & $\begin{array}{l}\text { LS (I.05) } \\
\text { FN }(0.83)\end{array}$ & $37,860(65.0)$ & $\begin{array}{l}\text { LS (I.03) } \\
\text { FN }(0.83)\end{array}$ & LS/FN (DXA) & Quartile \\
\hline $\begin{array}{l}\text { Burshell et al, }{ }^{10} \\
2008, \text { USA }\end{array}$ & $58(\mathrm{~N} / \mathrm{A})$ & N/A & $2,576(66.5)$ & N/A & LS/FN (DXA) & Two groups \\
\hline $\begin{array}{l}\text { Trémollieres et al," } \\
\text { 2008, France }\end{array}$ & $98(52.6)$ & $\begin{array}{l}\text { LS }(1.03) \\
\text { FN }(0.82)\end{array}$ & $2,137(53.2)$ & $\begin{array}{l}\text { LS (I.05) } \\
\text { FN }(0.85)\end{array}$ & LS/FN (DXA) & $\begin{array}{l}\text { Per I SD } \\
\text { increase }\end{array}$ \\
\hline $\begin{array}{l}\text { Stewart et al, }{ }^{12} \\
2005, \text { UK }\end{array}$ & $87(48.3)$ & $\begin{array}{l}\text { LS }(1.05) \\
\text { FN }(0.86)\end{array}$ & $3,013(48.6)$ & $\begin{array}{l}\text { LS }(1.06) \\
\text { FN }(0.88)\end{array}$ & LS/FN (DXA) & $\begin{array}{l}\text { Per I SD } \\
\text { increase }\end{array}$ \\
\hline $\begin{array}{l}\text { Ganry et al, }{ }^{13} 2004, \\
\text { France }\end{array}$ & $45(79.4)$ & $\mathrm{FN}(0.75)$ & $\mathrm{I}, 504(78.8)$ & $\mathrm{FN}(0.70)$ & $\begin{array}{l}\mathrm{FN} / \text { Trochanter/Ward's } \\
\text { triangle (DXA) }\end{array}$ & Tertile \\
\hline $\begin{array}{l}\text { van der Klift } \\
\text { et al, }{ }^{14} 2003 \text {, the } \\
\text { Netherlands }\end{array}$ & $74(65.5)$ & $\begin{array}{l}\text { LS (I.07) } \\
\text { FN (0.82) }\end{array}$ & $3,107(68.1)$ & $\begin{array}{l}\text { LS (I.03) } \\
\text { FN }(0.81)\end{array}$ & LS/FN (DXA) & $\begin{array}{l}\text { Tertile per I SD } \\
\text { increase }\end{array}$ \\
\hline $\begin{array}{l}\text { Buist et al, }{ }^{15} 200 \mathrm{I}, \\
\text { USA }\end{array}$ & $|3|(N / A)$ & $\mathrm{N} / \mathrm{A}$ & $8,203(68.2)$ & $\mathrm{TH}(0.76)$ & TH (DXA) & Quartile \\
\hline $\begin{array}{l}\text { Cauley et al, }{ }^{16} 1996, \\
\text { USA }\end{array}$ & 97 (7I.5) & $\begin{array}{l}\text { LS }(0.90) \\
\text { TH }(0.8 \mathrm{I})\end{array}$ & $6,854(71.9)$ & $\begin{array}{l}\text { LS }(0.84) \\
\text { TH }(0.75)\end{array}$ & $\begin{array}{l}\text { LS/TH/distal radius/ } \\
\text { proximal radius/calcaneus } \\
\text { (DXA) }\end{array}$ & $\begin{array}{l}\text { Quartile per I } \\
\text { SD increase }\end{array}$ \\
\hline
\end{tabular}

Abbreviations: BMD, bone mineral density; DXA, dual-energy X-ray absorptiometry; FN, femoral neck; LS, lumbar spine; N/A, not available; $T H$, total hip. 
Table 2 Adjustment for potential confounders in the included cohort studies

\begin{tabular}{|c|c|c|c|c|c|c|c|c|c|}
\hline \multirow[t]{2}{*}{ Author, year } & \multicolumn{8}{|c|}{ Adjustment for potential confounders in the primary analysis of each study } & \multirow[b]{2}{*}{ HRT use } \\
\hline & Age & Race & BMI & Smoking & Alcohol consumption & PA & Parity & Menopause & \\
\hline Nagel et al, 2017 & $\sqrt{ }$ & $\times$ & $\sqrt{ }$ & $\sqrt{ }$ & 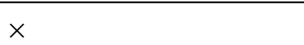 & $\sqrt{ }$ & $\times$ & $\sqrt{ }$ & $\sqrt{ }$ \\
\hline Fraenkel et al, ${ }^{8} 2013$ & $\sqrt{ }$ & $\times$ & $\sqrt{ }$ & $\times$ & $x$ & $x$ & $x$ & $x$ & $x$ \\
\hline Grenier et al, ${ }^{9} 201 \mathrm{I}$ & $\sqrt{ }$ & $x$ & $\sqrt{ }$ & $x$ & $x$ & $x$ & $x$ & $x$ & $\sqrt{ }$ \\
\hline Burshell et al, ${ }^{10} 2008$ & $\sqrt{ }$ & $x$ & $x$ & $\times$ & $x$ & $x$ & $x$ & $x$ & $x$ \\
\hline Trémollieres et al," 2008 & $x$ & $x$ & $x$ & $x$ & $x$ & $x$ & $x$ & $\sqrt{ }$ & $\sqrt{ }$ \\
\hline Stewart et al, ${ }^{12} 2005$ & $\sqrt{ }$ & $x$ & $\sqrt{ }$ & $x$ & $x$ & $x$ & $x$ & $\sqrt{ }$ & $\sqrt{ }$ \\
\hline Ganry et al, ${ }^{13} 2004$ & $\sqrt{ }$ & $x$ & $\sqrt{ }$ & $\sqrt{ }$ & $\sqrt{ }$ & $\sqrt{ }$ & $\sqrt{ }$ & $\sqrt{ }$ & $\sqrt{ }$ \\
\hline van der Klift et al, ${ }^{14} 2003$ & $\sqrt{ }$ & $x$ & $\sqrt{ }$ & $x$ & $x$ & $x$ & $x$ & $\sqrt{ }$ & $x$ \\
\hline Buist et al,,$^{15} 200 \mathrm{I}$ & $\sqrt{ }$ & $x$ & $\sqrt{ }$ & $x$ & $x$ & $x$ & $x$ & $\sqrt{ }$ & $x$ \\
\hline Cauley et al, ${ }^{16} 1996$ & $\sqrt{ }$ & $x$ & $\sqrt{ }$ & $\sqrt{ }$ & $\sqrt{ }$ & $\sqrt{ }$ & $\sqrt{ }$ & $\sqrt{ }$ & $x$ \\
\hline
\end{tabular}

Abbreviations: BMI, body mass index; HRT, hormone replacement therapy; PA, physical activity.

the analysis of BMD at the $\mathrm{FN}$ or $\mathrm{TH}$, we failed to detect an association between $\mathrm{BMD}$ and $\mathrm{BC}$ risk (summarized $\mathrm{RR}$ $=0.94 ; 95 \% \mathrm{CI}=0.66-1.33 ; I^{2}=72.5 \% ; P$ for heterogeneity $<0.001 ; n=8)$, as shown in Figure 3. The funnel plot and statistical analyses showed no evidence of publication bias (Figures S1 and S2).

In subgroup analyses, although the directions of the results were consistent with those of the main findings, not all subgroups showed statistical significance. For example, there was a significant association between BMD at the LS and the risk of BC in the subgroups of studies that used exposure units such as T-score or $z$ score. Furthermore, similar significant results for BMD at the LS and the risk of BC were observed in studies with a high risk of bias and studies with postmenopausal women. However, in metaregression analyses, there was no evidence of heterogeneity between the subgroups stratified by the study characteristics or those adjusted for confounding factors (Table 4), except in the analysis of BMD at the FN or TH. We obtained significant results for differences in the quality of studies in meta-regression analyses. Sensitivity analyses using an alternative statistical model showed robust results (data not shown). Additionally, the sensitivity analysis presented the summarized RR of BMD at the LS for the risk of BC ranged from $0.68\left(95 \% \mathrm{CI}=0.58-0.81 ; I^{2}=0 \%\right.$; exclusion of Cauley et $\left.\mathrm{al}^{16}\right)$ to $0.79\left(95 \% \mathrm{CI}=0.58-1.07 ; I^{2}=31.5 \%\right.$; exclusion of Grenier et $\mathrm{al}^{9}$ ). Moreover, the sensitivity analysis presented the summarized RR of BMD at the FN or TH for the risk of $\mathrm{BC}$ ranged from 0.85 (95\% $\mathrm{CI}=0.61-1.19 ; I^{2}=69.5 \%$; exclusion of Ganry et $\left.\mathrm{al}^{13}\right)$ to $1.13\left(95 \% \mathrm{CI}=0.82-1.56 ; I^{2}=55.8 \%\right.$; exclusion of Fraenkel et $\mathrm{al}^{8}$ ). For BMD at the FN or TH, when the studies that contributed the largest amount to betweenstudy heterogeneity were sequentially excluded until $I^{2}$ was
$<50 \%$, the summarized HR was $1.03(95 \% \mathrm{CI}=0.78-1.37$; $I^{2}=43.4 \%$ ), which was similar to the original estimate.

\section{$\mathrm{BMD}$ and $\mathrm{BC}$ risk (dose-response analysis)}

Four studies were included in the dose-response analysis of BMD at the LS, with 234 BC patients among 11,237 participants. The summary RR was 0.94 (95\% CI =0.82-1.07) for each $0.1 \mathrm{~g} / \mathrm{cm}^{2}$ incremental change in BMD at the LS, with moderate heterogeneity $\left(I^{2}=59.6 \% ; P\right.$ for heterogeneity $=0.059$ ), as shown in Figure 4. Furthermore, four studies were included in the dose-response analysis of BMD at the FN or TH, with $227 \mathrm{BC}$ patients among 6,668 participants. The summary RR was 0.94 (95\% CI =0.73-1.22) for each $0.1 \mathrm{~g} / \mathrm{cm}^{2}$ incremental change in BMD at the $\mathrm{FN}$ or TH, with significant heterogeneity $\left(I^{2}=71.6 \% ; P\right.$ for heterogeneity $=0.014$ ), as shown in Figure 5 .

\section{Discussion}

On the basis of the ten included cohort studies, we found a significant association between BMD at the LS and the risk of BC in a categorical meta-analysis. However, no significant association was observed between BMD at the FN or TH and the risk of BC. Similar null findings were also observed in dose-response meta-analyses.

The present meta-analysis has several strengths. Since we carried out the analyses on the basis of prospective cohort studies, we have effectively avoided recall bias and reduced the possibility of selection bias. Compared with previous meta-analyses, we conducted more detailed subgroup analyses and dose-response analyses. This meta-analysis may also have several limitations that must be taken into consideration. BMD may be associated with other factors, including body 


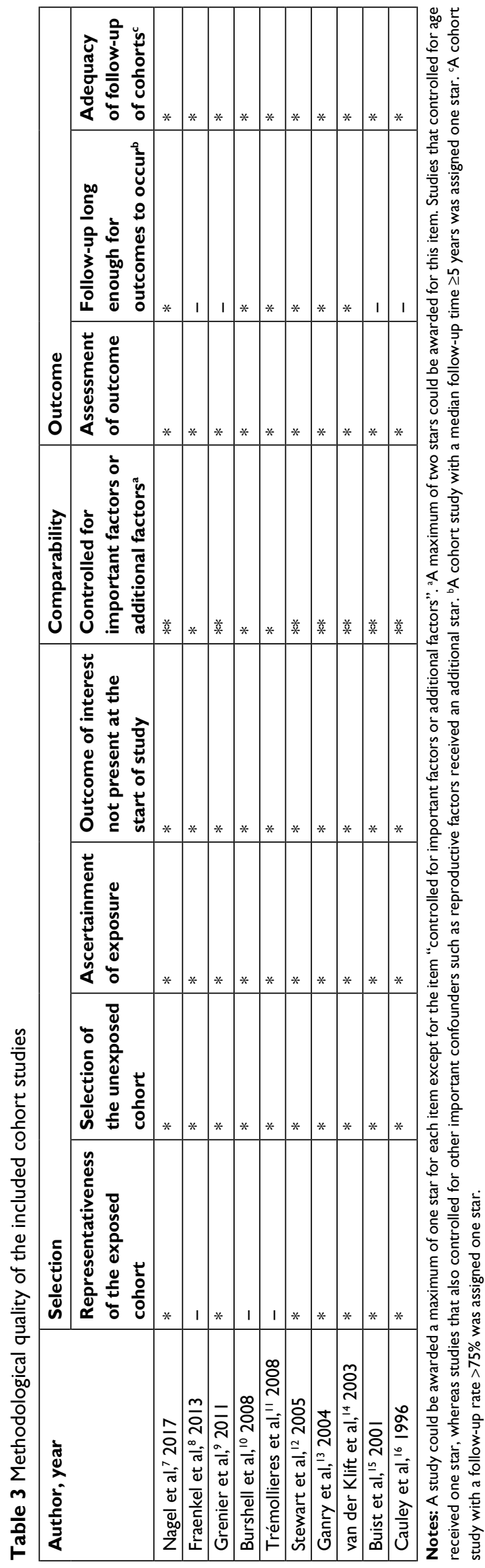

mass index, physical activity, alcohol consumption, smoking, reproductive factors, and the use of HRT, which could possibly confound the associations we observed. The direction of results for BMD at the LS persisted in studies that adjusted for these potential confounders; however, statistical significance was only observed in these studies adjusting for body mass index. We could not easily interpret these results because of the limited number of studies in some of these subgroup analyses. There was no evidence of heterogeneity between these subgroups with and without adjustment for these potentially confounding factors. For BMD at the FN or TH, although null results were observed throughout the main subgroup analyses, the direction of the results was not consistent. Further studies are needed to fully adjust for these potential confounders in the future. Second, a high degree of heterogeneity was observed in the analysis of BMD at the FN or TH. In the subgroup analyses, according to study characteristics with adjustment for potential confounders, many of the $I^{2}$ estimates were judged to be moderate or high. Although we explored the potential sources of heterogeneity, because of the scarcity of the data, most causes of heterogeneity could not be identified. It is noteworthy that we found only study quality to be a source of heterogeneity $(P=0.042)$. These issues may reduce the strength of the conclusions that can be drawn from this meta-analysis. Furthermore, after excluding the study performed by Cauley et $\mathrm{al}^{16}$ in 1996, we observed significant results in the categorical and doseresponse analyses. Notably, in that study, they measured BMD twice by different methods, which may explain the significant results we obtained after the exclusion of that study. Third, a limited number of included studies provided information that could be used in the dose-response analyses. Therefore, we could only conduct the dose-response analysis with a limited number of studies. ${ }^{7,11-14,16}$ Since the BMD measurement units varied among the included studies, a future meta-analysis should perform another dose-response analysis to clarify the association between BMD and the risk of BC. Fourth, the quality of the included studies varied. Interestingly, we only generated significant results after summarizing the high-risk studies, although this phenomenon might be attributed to the limited number of studies. Lastly, most studies investigating BMD and BC risk combined both estrogen receptor (ER)-positive and ER-negative tumors as a single outcome, although estrogen is primarily associated with the development of ER-positive cancers. Furthermore, an ER mutation in the ER isoform has been described by Fuqua et $\mathrm{al}^{27}$ that is associated with the increased proliferation of $\mathrm{BC}$ cells and that has been found in a high percentage of patients with 


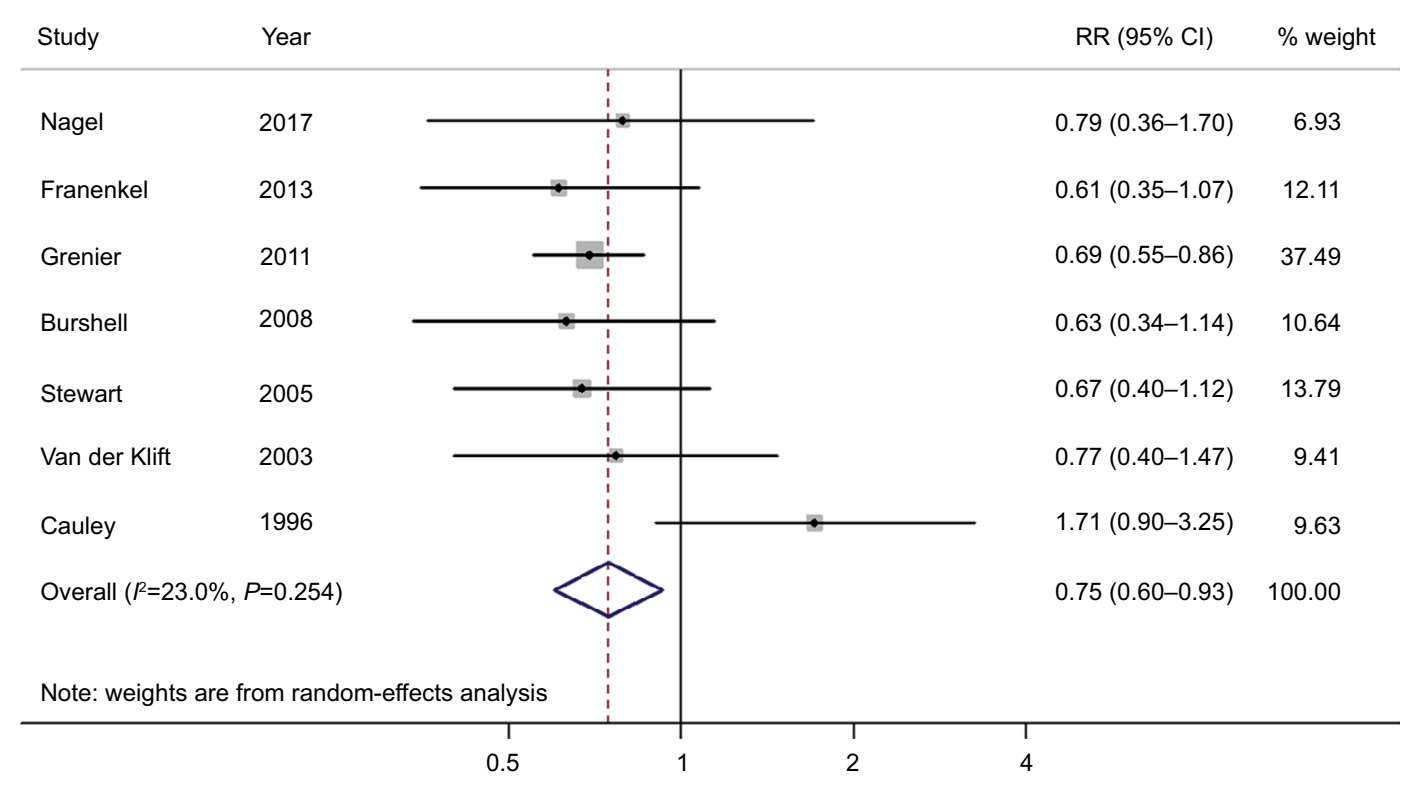

Figure 2 Forest plot (random-effects model) of bone mineral density at the lumbar spine and the risk of breast cancer.

Note: The squares indicate study-specific RRs (the size of the square reflects the study-specific statistical weight); the horizontal lines indicate $95 \%$ Cls; and the diamond indicates the summary RR estimate with its $95 \% \mathrm{Cl}$.

Abbreviation: $R R$, relative risk.

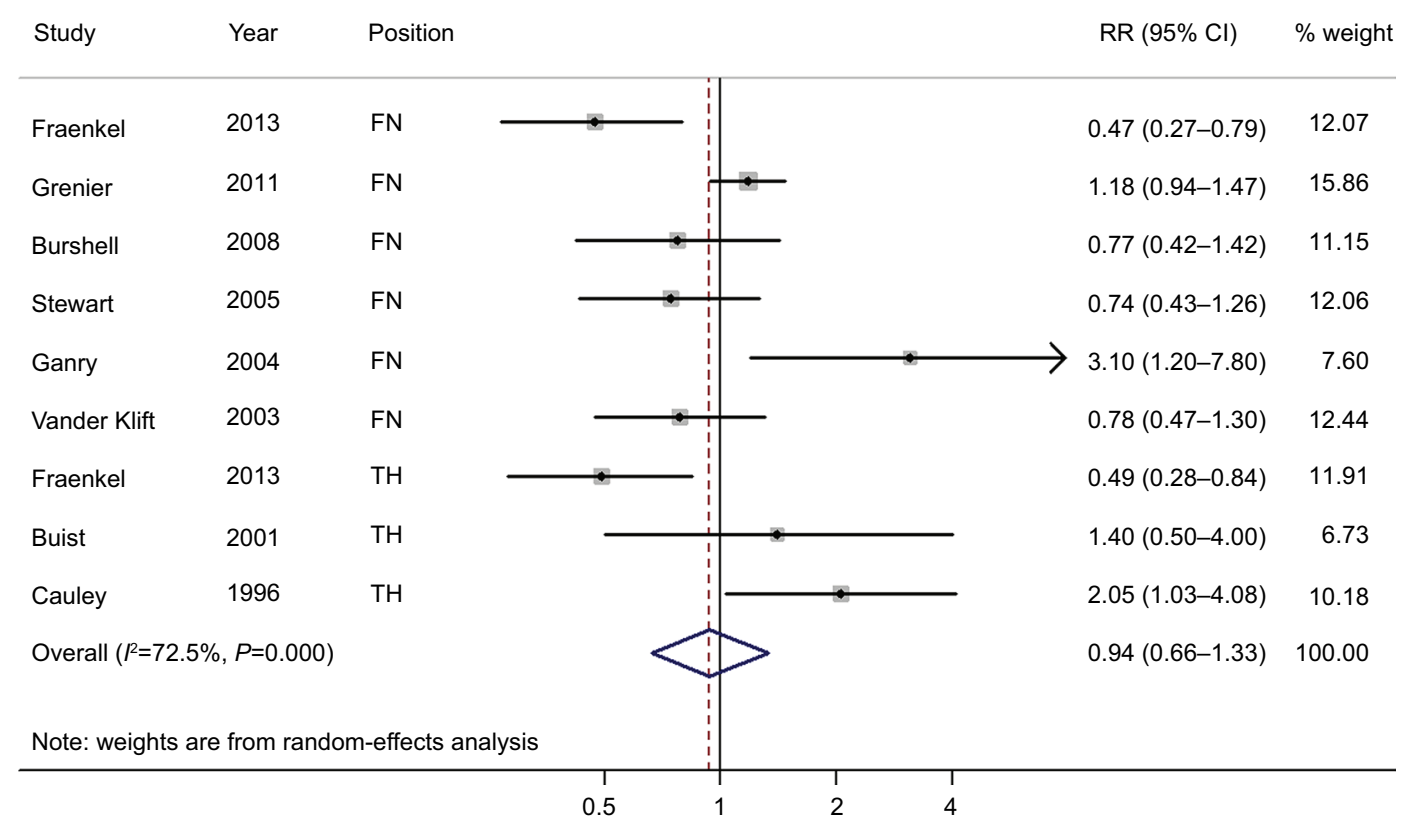

Figure 3 Forest plot (random-effects model) of bone mineral density at the $\mathrm{FN}$ or TH and the risk of breast cancer.

Note: The squares indicate study-specific RRs (the size of the square reflects the study-specific statistical weight); the horizontal lines indicate $95 \%$ Cls; and the diamond indicates the summary RR estimate with its $95 \% \mathrm{Cl}$.

Abbreviations: FN, femoral neck; RR, relative risk; TH, total hip.

hyperplastic breast tissue. ${ }^{28}$ If such a mutation was present in both the bone and breast tissue, very low levels of estradiol could preserve BMD and still increase the risk of BC. However, only one included study ${ }^{12}$ provided risk estimates stratified by ER status.
In addition to the effects of different study designs, BMD measurement sites, BMD measurement methods, and characteristics of study participants, the inconsistent findings of these published studies might also be attributed to the different menopausal status of the participants in various studies. 
Table 4 Risk estimate summary of the association between bone mineral density and the risk of breast cancer (highest category vs lowest category)

\begin{tabular}{|c|c|c|c|c|c|c|c|c|c|c|c|c|}
\hline & \multicolumn{6}{|c|}{ Lumbar spine } & \multicolumn{6}{|c|}{ Femoral neck or total hip } \\
\hline & $\begin{array}{l}\text { No. of } \\
\text { studies }\end{array}$ & $\mathbf{R R}$ & $95 \% \mathrm{Cl}$ & $I^{2}(\%)$ & $P_{\mathrm{h}}{ }^{a}$ & $P_{h}{ }^{b}$ & $\begin{array}{l}\text { No. of } \\
\text { studies }\end{array}$ & HR & $95 \% \mathrm{Cl}$ & $P^{2}(\%)$ & $P_{\mathrm{h}}{ }^{\mathrm{a}}$ & $P_{\mathrm{h}}{ }^{\mathrm{b}}$ \\
\hline Overall & 7 & 0.75 & $0.60-0.93$ & 23.0 & 0.254 & & 9 & 0.94 & $0.66-1.33$ & 72.5 & $<0.001$ & \\
\hline \multicolumn{13}{|l|}{ Subgroup analyses } \\
\hline Geographic location & & & & & & 0.842 & & & & & & 0.189 \\
\hline North America & 3 & 0.86 & $0.5 \mathrm{I}-\mathrm{I} .47$ & 72.1 & 0.028 & & 4 & 1.21 & $0.87-1.67$ & 32.7 & 0.216 & \\
\hline Europe & 3 & 0.72 & $0.5 \mathrm{I}-\mathrm{I} .04$ & 0 & 0.918 & & 3 & 1.09 & $0.54-2.21$ & 73.4 & 0.023 & \\
\hline Others & 1 & 0.61 & $0.35-1.07$ & $\mathrm{~N} / \mathrm{A}$ & $\mathrm{N} / \mathrm{A}$ & & 2 & 0.48 & $0.33-0.70$ & 0 & 0.915 & \\
\hline No. of cases & & & & & & $0.88 \mathrm{I}$ & & & & & & 0.289 \\
\hline$\geq 50$ & 5 & 0.75 & $0.56-1.01$ & 48.1 & 0.103 & & 6 & 0.82 & $0.54-1.25$ & 77.1 & 0.001 & \\
\hline$<50$ & 2 & 0.78 & $0.47-1.28$ & 0 & 0.960 & & 3 & 1.40 & $0.60-3.31$ & 70.0 & 0.036 & \\
\hline Exposure unit & & & & & & 0.225 & & & & & & 0.150 \\
\hline $\mathrm{g} / \mathrm{cm}^{2}$ & 4 & 0.90 & $0.59-1.39$ & 44.7 & 0.143 & & 5 & 1.28 & $0.75-2.19$ & 66.4 & 0.018 & \\
\hline Others & 3 & 0.67 & $0.55-0.82$ & 0 & 0.899 & & 4 & 0.70 & $0.41-1.19$ & 81.4 & 0.001 & \\
\hline Study quality & & & & & & 0.409 & & & & & & 0.042 \\
\hline Low risk of bias & 5 & 0.81 & $0.60-1.10$ & 43.4 & 0.132 & & 6 & 1.21 & $0.85-1.73$ & 58.4 & 0.034 & \\
\hline High risk of bias & 2 & 0.62 & $0.4 I-0.93$ & 0 & 0.939 & & 3 & 0.55 & $0.40-0.76$ & 0 & 0.434 & \\
\hline Menopausal status & & & & & & 0.289 & & & & & & 0.482 \\
\hline Postmenopausal & 3 & 0.68 & $0.56-0.83$ & 0 & 0.960 & & 4 & 1.09 & $0.7 I-I .69$ & 64.6 & 0.037 & \\
\hline Not postmenopausal & 4 & 0.89 & $0.56-1.40$ & 50.0 & 0.112 & & 5 & 0.82 & $0.48-|.4|$ & 73.0 & 0.005 & \\
\hline \multicolumn{13}{|c|}{$\begin{array}{l}\text { Adjustment for potential confounders or risk } \\
\text { factors }\end{array}$} \\
\hline BMI & & & & & & 0.646 & & & & & & 0.736 \\
\hline Yes & 6 & 0.77 & $0.60-0.99$ & 33.8 & 0.182 & & 8 & 0.97 & $0.66-1.42$ & 75.4 & $<0.001$ & \\
\hline No & I & 0.63 & $0.34-1.14$ & $\mathrm{~N} / \mathrm{A}$ & $\mathrm{N} / \mathrm{A}$ & & $\mathrm{I}$ & 0.77 & $0.42-1.42$ & $\mathrm{~N} / \mathrm{A}$ & $\mathrm{N} / \mathrm{A}$ & \\
\hline Menopausal status & & & & & & 0.225 & & & & & & 0.666 \\
\hline Yes & 4 & 0.90 & $0.59-1.39$ & 44.7 & 0.143 & & 3 & 1.09 & $0.54-2.21$ & 73.4 & 0.023 & \\
\hline No & 3 & 0.67 & $0.55-0.82$ & 0 & 0.899 & & 6 & 0.89 & $0.57-1.39$ & 76.7 & 0.001 & \\
\hline HRT use & & & & & & $0.47 \mathrm{I}$ & & & & & & 0.844 \\
\hline Yes & 4 & 0.84 & $0.57-1.23$ & 57.5 & 0.070 & & 4 & 0.99 & $0.56-1.75$ & 80.3 & 0.002 & \\
\hline No & 3 & 0.66 & $0.47-0.93$ & 0 & 0.854 & & 5 & 0.90 & $0.55-1.49$ & 66.7 & 0.017 & \\
\hline $\begin{array}{l}\text { Any reproductive } \\
\text { factors }\end{array}$ & & & & & & 0.409 & & & & & & 0.229 \\
\hline Yes & 5 & 0.81 & $0.60-1.10$ & 43.4 & 0.132 & & 7 & 1.07 & $0.73-1.58$ & 70.6 & 0.002 & \\
\hline No & 2 & 0.62 & $0.4 I-0.93$ & 0 & 0.939 & & 2 & 0.59 & $0.36-0.95$ & 29.6 & 0.233 & \\
\hline
\end{tabular}

Notes: ${ }^{a}$-value for heterogeneity within each subgroup. ${ }^{b} P$-value for heterogeneity between subgroups according to the meta-regression analysis.

Abbreviations: BMI, body mass index; HRT, hormone replacement therapy; N/A, not available; RR, relative risk.

Significant results were observed in the analysis of BMD at the LS in postmenopausal participants (Table 4). Because BMD could be a marker of cumulative exposure to estrogen, this effect could be more apparent in postmenopausal women than in premenopausal women. Furthermore, the rates of HRT use were different among these studies. For example, Stewart et a ${ }^{12}$ reported that over half the women had received HRT at some point by the end of the study in a population-based screening program for osteoporosis risk. Additionally, they found that those with low baseline levels of BMD were more likely to receive HRT. However, the Framingham ${ }^{29}$ and Rotterdam ${ }^{14}$ studies included all subjects and had $17.7 \%$ and $10.2 \%$ of their participants who reported the use of HRT, respectively. Therefore, it may be that those in the lowest quartile of BMD were taking HRT, thereby increasing their risk of $\mathrm{BC}$ and while not increasing their BMD. Although we could not perform an analysis stratified by the use of HRT, interestingly, we found significant results in the subgroup analysis that did not adjust for HRT use. More studies should focus on this issue.

In summary, on the basis of the present meta-analysis, we were unable to demonstrate an association between BMD and the risk of $\mathrm{BC}$. 


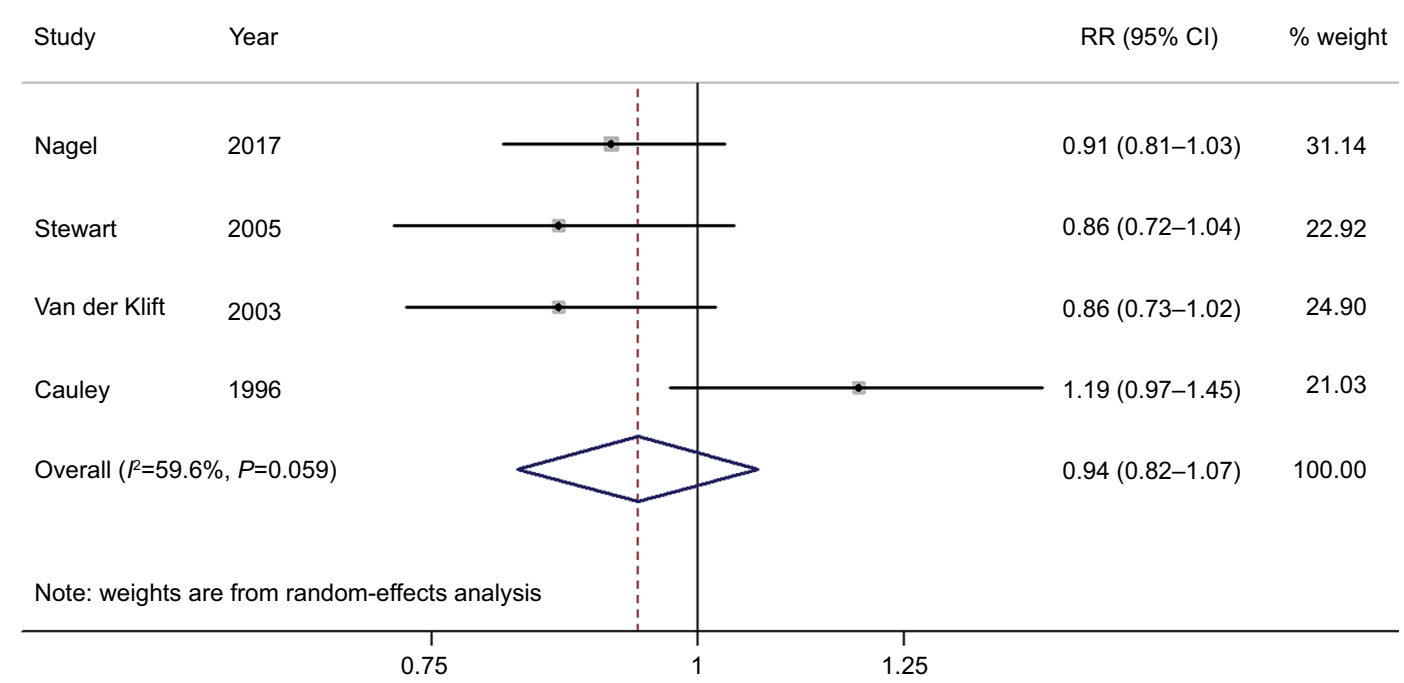

Figure 4 Forest plot (random-effects model) of BMD at the lumbar spine and the risk of breast cancer in the dose-response analysis (per $0.1 \mathrm{~g} / \mathrm{cm}^{2}$ incremental change in BMD).

Note: The squares indicate study-specific relative risks (the size of the square reflects the study-specific statistical weight); the horizontal lines indicate $95 \%$ Cls; and the diamond indicates the summary RR estimate with its $95 \% \mathrm{Cl}$.

Abbreviations: BMD, bone mineral density; RR, relative risk.

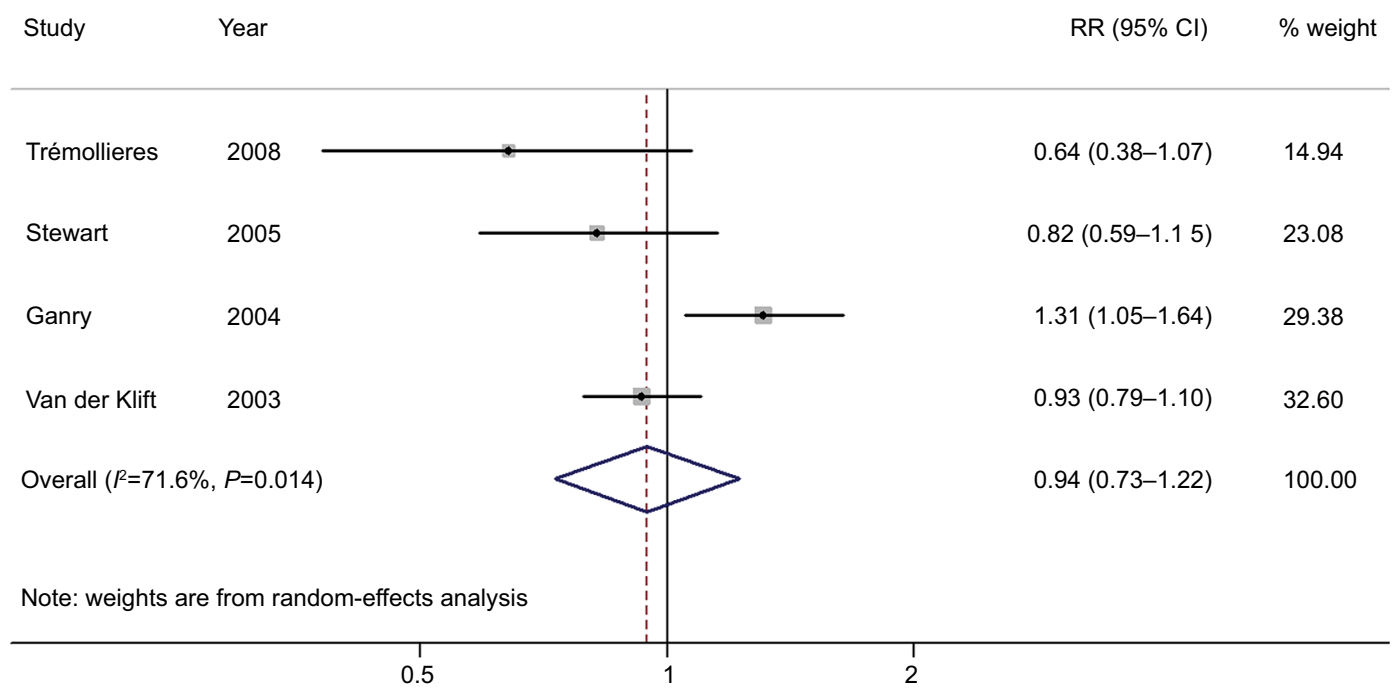

Figure 5 Forest plot (random-effects model) of bone mineral density at the femoral neck or total hip and the risk of breast cancer.

Note: The squares indicate study-specific relative risks (the size of the square reflects the study-specific statistical weight); the horizontal lines indicate $95 \%$ Cls; and the diamond indicates the summary RR estimate with its $95 \% \mathrm{Cl}$.

Abbreviation: RR, relative risk.

\section{Author contributions}

J-HC, QY, Y-NM, and D-LW designed the research; J-HC and QY conducted the research; QY and S-HZ analyzed data; J-HC and QY wrote the draft; and all authors contributed to data analysis, drafting and revising the article, gave final approval of the version to be published, and agree to be accountable for all aspects of the work.

\section{Disclosure}

The authors report no conflicts of interest in this work.

\section{References}

1. Torre LA, Bray F, Siegel RL, Ferlay J, Lortet-Tieulent J, Jemal A. Global cancer statistics, 2012. CA Cancer J Clin. 2015;65(2):87-108.

2. Siegel RL, Miller KD, Jemal A. Cancer statistics, 2018. CA Cancer J Clin. 2018;68(1):7-30.

3. Rojas K, Stuckey A. Breast cancer epidemiology and risk factors. Clin Obstet Gynecol. 2016;59(4):651-672.

4. Väänänen HK, Härkönen PL. Estrogen and bone metabolism. Maturitas. 1996;23 Suppl:S65-S69.

5. Guthrie JR, Lehert P, Dennerstein L, Burger HG, Ebeling PR, Wark JD. The relative effect of endogenous estradiol and androgens on menopausal bone loss: a longitudinal study. Osteoporos Int. 2004;15(11): $881-886$. 
6. Rapuri PB, Gallagher JC, Haynatzki G. Endogenous levels of serum estradiol and sex hormone binding globulin determine bone mineral density, bone remodeling, the rate of bone loss, and response to treatment with estrogen in elderly women. J Clin Endocrinol Metab. 2004;89(10):4954-4962.

7. Nagel G, Peter RS, Klotz E, Brozek W, Concin H. Bone mineral density and breast cancer risk: results from the Vorarlberg Health Monitoring \& Prevention Program and meta-analysis. Bone Rep. 2017;7:83-89.

8. Fraenkel M, Novack V, Liel Y, et al. Association between bone mineral density and incidence of breast cancer. PLoS One. 2013;8(8):e70980.

9. Grenier D, Cooke AL, Lix L, Metge C, Lu H, Leslie WD. Bone mineral density and risk of postmenopausal breast cancer. Breast Cancer Res Treat. 2011;126(3):679-686.

10. Burshell AL, Song J, Dowsett SA, et al. Relationship between bone mass, invasive breast cancer incidence and raloxifene therapy in postmenopausal women with low bone mass or osteoporosis. Curr Med Res Opin. 2008;24(3):807-813.

11. Trémollieres FA, Pouillès JM, Laparra J, Ribot C. Bone mineral density at menopause does not predict breast cancer incidence. Osteoporos Int. 2008;19(10):1497-1504.

12. Stewart A, Kumar V, Torgerson DJ, Fraser WD, Gilbert FJ, Reid DM. Axial BMD, change in BMD and bone turnover do not predict breast cancer incidence in early postmenopausal women. Osteoporos Int. 2005;16(12):1627-1632.

13. Ganry O, Baudoin C, Fardellone P, Peng J, Raverdy N. Bone mass density and risk of breast cancer and survival in older women. Eur $J$ Epidemiol. 2004;19(8):785-792.

14. van der Klift M, de Laet CE, Coebergh JW, Hofman A, Pols HA; Rotterdam Study. Bone mineral density and the risk of breast cancer: the Rotterdam study. Bone. 2003;32(3):211-216.

15. Buist DS, Lacroix AZ, Barlow WE, et al. Bone mineral density and endogenous hormones and risk of breast cancer in postmenopausal women (United States). Cancer Causes Control. 2001;12(3):213-222.

16. Cauley JA, Lucas FL, Kuller LH, Vogt MT, Browner WS, Cummings SR. Bone mineral density and risk of breast cancer in older women: the study of osteoporotic fractures. Study of Osteoporotic Fractures Research Group. JAMA. 1996;276(17):1404-1408.

17. Moher D, Liberati A, Tetzlaff J, Altman DG; PRISMA Group. Preferred reporting items for systematic reviews and meta-analyses: the PRISMA statement. BMJ. 2009;339:b2535.
18. Wells GA, Shea B, O'Connell D, et al. The Newcastle-Ottawa scale (NOS) for assessing the quality of nonrandomised studies in metaanalyses. Available from: http://www.ohri.ca/programs/clinical_epidemiological/oxford.asp. Accessed August 26, 2018.

19. Danesh J, Collins R, Appleby P, Peto R. Association of fibrinogen, C-reactive protein, albumin, or leukocyte count with coronary heart disease: meta-analyses of prospective studies. JAMA. 1998;279(18):1477-1482.

20. Hamling J, Lee P, Weitkunat R, Ambühl M. Facilitating meta-analyses by deriving relative effect and precision estimates for alternative comparisons from a set of estimates presented by exposure level or disease category. Stat Med. 2008;27(7):954-970.

21. Greenland S, Longnecker MP. Methods for trend estimation from summarized dose-response data, with applications to meta-analysis. Am J Epidemiol. 1992;135(11):1301-1309.

22. Higgins JP, Thompson SG. Quantifying heterogeneity in a meta-analysis. Stat Med. 2002;21(11):1539-1558.

23. Egger M, Davey Smith G, Schneider M, Minder C. Bias in metaanalysis detected by a simple, graphical test. BMJ. 1997;315(7109): 629-634.

24. Begg CB, Mazumdar M. Operating characteristics of a RANK correlation test for publication bias. Biometrics. 1994;50(4):1088-1101.

25. Patsopoulos NA, Evangelou E, Ioannidis JP. Sensitivity of betweenstudy heterogeneity in meta-analysis: proposed metrics and empirical evaluation. Int J Epidemiol. 2008;37(5):1148-1157.

26. Odutayo A, Wong CX, Hsiao AJ, Hopewell S, Altman DG, Emdin CA. Atrial fibrillation and risks of cardiovascular disease, renal disease, and death: systematic review and meta-analysis. BMJ. 2016;354:i4482.

27. Fuqua SA, Wiltschke C, Zhang QX, et al. A hypersensitive estrogen receptor-alpha mutation in premalignant breast lesions. Cancer Res. 2000;60(15):4026-4029.

28. Cauley JA, Song J, Dowsett SA, Mershon JL, Cummings SR. Risk factors for breast cancer in older women: the relative contribution of bone mineral density and other established risk factors. Breast Cancer Res Treat. 2007;102(2):181-188.

29. Zhang Y, Kiel DP, Kreger BE, et al. Bone mass and the risk of breast cancer among postmenopausal women. $N$ Engl J Med. 1997;336(9): 611-617. 


\section{Supplementary materials}

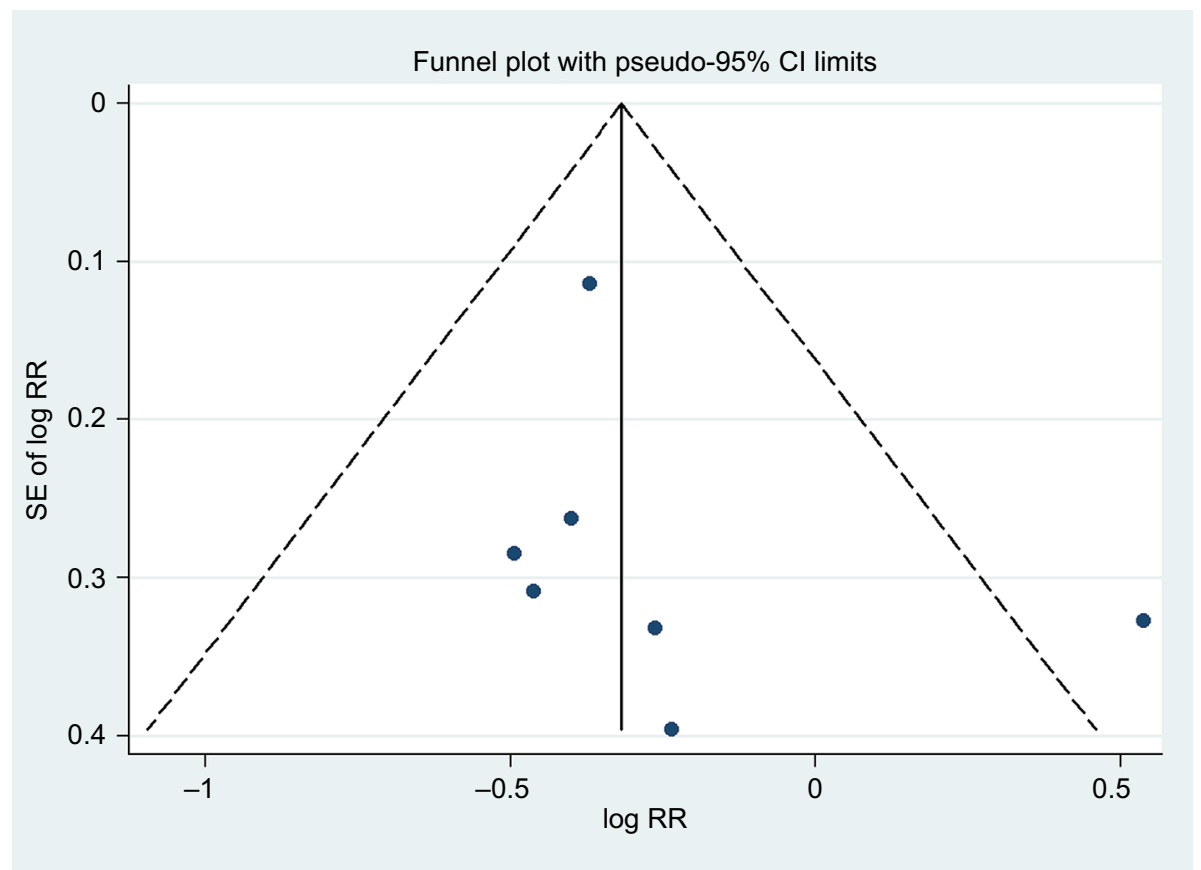

Figure SI Test for publication bias for bone mineral density at the lumbar spine through Begg's funnel plot.

Notes: The circles represent real studies. The vertical lines represent the summary effect estimates, and the dashed lines represent pseudo-95\% $\mathrm{Cl}$ limits. Abbreviations: RR, relative risk; SE, standard error.

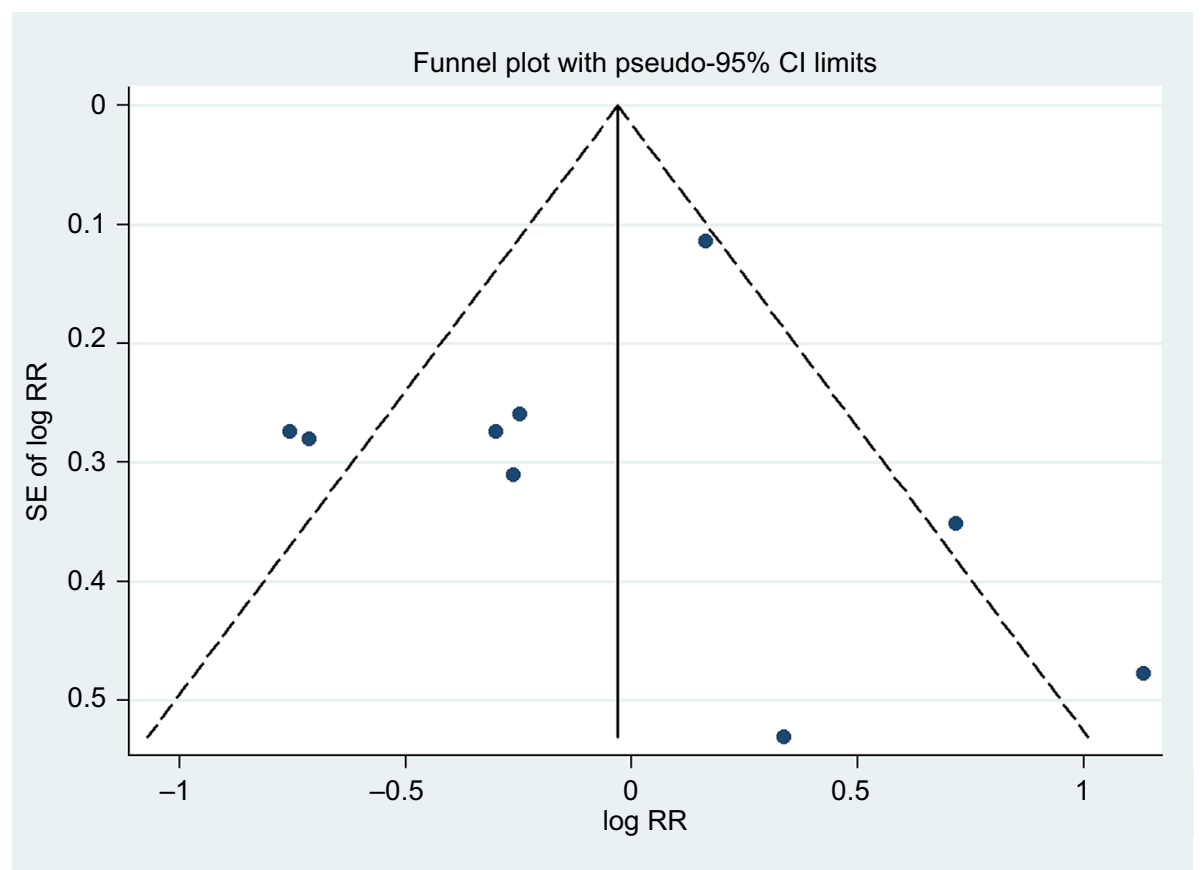

Figure S2 Test for publication bias for bone mineral density at the femoral neck or total hip through Begg's funnel plot.

Notes: The circles represent real studies. The vertical lines represent the summary effect estimates, and the dashed lines represent pseudo-95\% Cl limits. Abbreviations: RR, relative risk; SE, standard error. 


\section{Publish your work in this journal}

Cancer Management and Research is an international, peer-reviewed open access journal focusing on cancer research and the optimal use of preventative and integrated treatment interventions to achieve improved outcomes, enhanced survival and quality of life for the cancer patient. The manuscript management system is completely online and includes a very quick and fair peer-review system, which is all easy to use. Visit http://www.dovepress.com/testimonials.php to read real quotes from published authors. 